\title{
Zearalenone induces apoptosis in bovine mammary epithelial cells by activating endoplasmic reticulum stress
}

\author{
YuRong Fu, ${ }^{1 *}$ YongCheng Jin, ${ }^{1 *}$ Yun Zhao, ${ }^{1}$ AnShan Shan, ${ }^{2}$ HengTong Fang, ${ }^{1}$ JingLin Shen, ${ }^{1}$ ChangHai Zhou, ${ }^{1}$ \\ Hao Yu, ${ }^{1}$ Yong Feng Zhou, ${ }^{1}$ Xin Wang, ${ }^{1}$ JunMei Wang, ${ }^{1}$ RuiHua Li, ${ }^{1}$ Rui Wang, ${ }^{1}$ and Jing Zhang $^{1} \dagger$ \\ ${ }^{1}$ College of Animal Science, Jilin University, Changchun 130062, People's Republic of China \\ ${ }^{2}$ Institute of Animal Nutrition, Northeast Agricultural University, Harbin 150030, People's Republic of China
}

\section{ABSTRACT}

Zearalenone (ZEA) is a common mycotoxin produced by fungi within the genus Fusarium. However, few studies have examined the direct effects of the toxin on the mammary glands. In the present study, the effects of ZEA treatment on bovine mammary epithelial cells (MAC-T) from dairy cows were investigated. The cells were treated with different concentrations of ZEA to evaluate the effect of the toxin on cell viability, intracellular reactive oxygen species (ROS) concentrations, mitochondrial membrane potential, endoplasmic reticulum (ER) stress, and the expression of apoptosis-related genes. The results indicated that different concentrations $(5,10,15,20,25,30,50,60$, or $100 \mu M)$ of ZEA were able to inhibit growth of MAC-T cells. After exposing the MAC-T cells to $30 \mu M$ ZEA, compared with the control group, ROS levels increased, mitochondrial membrane potential decreased, and mRNA expression of the ER-specific stress-related genes GRP $78, H^{\prime} P^{70}$, ATF6, EIF2A, ASK1, and CHOP was upregulated in the ZEA-treated group. Further, we analyzed the increase in apoptotic rate by flow cytometry. At the mRNA level, compared with the control group, the expression of the apoptosis-promoting gene $B A X$ was increased in the ZEA-treated group, the expression of the inhibitory gene $B C L 2$ decreased, and the expression of the gene $C A S P 3$ increased. We observed a significant increase in caspase-3 activity in ZEA-treated MAC$\mathrm{T}$ cells. Furthermore, the apoptotic rate of the cells in the ZEA group treated with 4-phenylbutyric acid (ER stress inhibitor) decreased and the mRNA expression levels of ER stress markers GRP 78 and CHOP decreased. Compared with the ZEA treatment group, the mRNA expression level of the apoptosis-related gene $B A X$ was decreased and the expression level of

Received December 27, 2018.

Accepted July 24, 2019.

*These authors contributed equally to this work.

†Corresponding author: zhang_jing99@jlu.edu.cn
$B C L 2$ was increased in the ZEA + 4-phenylbutyric acid cotreatment group. These findings indicate that ZEAinduced ER stress increases apoptosis in MAC-T cells. The treatment of MAC-T cells with ZEA reduced cell viability, increased ROS content, decreased mitochondrial membrane potential, increased ER stress marker expression, and induced apoptosis.

Key words: zearalenone, endoplasmic reticulum stress, apoptosis, bovine mammary epithelial cell

\section{INTRODUCTION}

Zearalenone (ZEA) is a biological toxin produced by several species of Fusarium fungi. The toxin can be widely detected in cereal crops, including corn, barley, wheat, and sorghum. Furthermore, ingestion of the toxin is potentially harmful to humans and animals alike (Jiménez and Mateo, 1997; Abassi et al., 2016). This toxin has been observed to exhibit genotoxicity (Lioi et al., 2004a), immunotoxicity (Ben Salah-Abbès et al., 2008), and reproductive toxicity and often leads to liver (Lee et al., 2013), kidney (Farb et al., 1976), and intestinal tract (Wang et al., 2018) damage. It has been reported that ZEA has a negative effect on meiosis in bovine oocytes and germ cells (Yang et al., 2018). Dairy cows are economically important animals, and their milk production performance and quality of milk are the most important indicators for economic success. As such, healthy mammary epithelial cells are crucial for optimal milk production and quality. Previous studies have reported an increase in oxidative stress during late pregnancy and early lactation, resulting in reduced milk production in sows (Tan et al., 2015). In dairy cows, the mammary glands are widely considered to be some of the most metabolically active tissues. Furthermore, the metabolic rate of mammary epithelial cells greatly increases during lactation. When oxidative stress occurs, the mammary gland cells risk extensive damage, causing rapid aging and apoptosis and making the tissues prone to mastitis (Mori et al., 2004). Recent studies have reported that ZEA exposure likely contrib- 
utes to the development of endocrine disorders in mammary tissues of female rats, increasing the likelihood of breast cancer (Belli et al., 2010). It has also been demonstrated that ZEA not only inhibits the growth of human breast cancer cells but affects the cell cycle (Miranda et al., 2011).

It has been reported that ZEA causes an increase in the oxidative stress and reactive oxygen species (ROS) levels in HepG2 and CHO-K1 cells (Tatay et al., 2016, 2017). In studies of murine TM4 cells treated with ZEA, it was demonstrated that ROS regulates ZEA-induced cell cycle arrest and apoptosis through endoplasmic reticulum (ER) stress (Zheng et al., 2018). Mitochondria are also able to induce apoptosis by altering the redox potential of cells through an increase in the production of ROS (Lee et al., 2018).

Proteins are synthesized by ribosomes in the cytosol and synthesized proteins transported into the ER. Both intracellular and export proteins are synthesized in the same way (Shore et al., 2011). Stresses to the ER lead to the activation of 3 transmembrane signaling proteins: PERK, IRE1, and ATF6 (Sovolyova et al., 2014). Endoplasmic reticulum stress activates the specific molecular chaperone GRP78, also known as Bip, whereas $\mathrm{CHOP}$ is an apoptotic transcription factor that is expressed at low levels in the absence of stimuli. When a cell is exposed to a stressor, expression of $C H O P$ is upregulated (Endo et al., 2006). If the ER stress persists or is too severe to return to homeostasis, the cells will proceed down a pro-apoptotic pathway. The protein $\mathrm{CHOP}$ contributes to this process by inhibiting the expression of anti-apoptotic BCL2 (Chen et al., 2008; Kamp et al., 2013).

Despite what it is known about milk production and the toxic effects of ZEA, little is known about the specific effects of ZEA on mammary epithelial cells, ROS production, and induction of ER stress. Furthermore, whether these effects result in progression down the pathway to apoptosis remains unknown. In this study, the effect of ZEA on the development of apoptosis in the mammary gland epithelial cell line, MAC-T, was examined. In addition, we sought to determine whether this process is associated with ER stress.

\section{MATERIALS AND METHODS}

\section{Chemicals and Reagents}

Zearalenone (purity >99\%), hydrocortisone, penicillin-streptomycin, insulin, and 4-phenylbutyric acid (4PBA) were purchased from Sigma-Aldrich (St. Louis, MO). Zearalenone was dissolved in dimethyl sulfoxide to prepare a stock solution and stored at $-20^{\circ} \mathrm{C}$. Fetal bovine serum was purchased from Gibco (Gaithersburg,
MD). Dulbecco's modified Eagle's/high-glucose medium was purchased from Hyclone (Logan, UT). The cell counting kit-8 (CCK-8) was purchased from Dojindo Laboratories (Kumamoto, Japan), and the fluorescein isothiocyanate (FITC) annexin V apoptosis detection kit was purchased from BD Biosciences (San Jose, CA). The ROS assay and mitochondrial membrane potential, JC-1, and caspase-3 activity assay kits were obtained from Beyotime Biotechnology (Shanghai, China).

\section{Cell Culture}

The bovine mammary epithelial cell line MAC-T was kindly provided by Hong Gu Lee (Konkuk University, Seoul, Republic of Korea). We measured the cell count and confirmed a logarithmic growth phase close to $17 \mathrm{~h}$ (ATCC CRL-10274). The growth and differentiation of cells were observed under a microscope and conformed to the morphology of MAC-T cells (Zavizion et al., 1995). We also detected that the mRNA expression levels of $\alpha-\mathrm{CN}$ and $\beta-\mathrm{CN}$ significantly increased in differentiated MAC-T cells (growth medium supplemented with prolactin). We detected 3.1-, 3.3-, and 15.1-fold $(P<0.01)$ expressions of $\beta-\mathrm{CN}$ at 1,2 , and $4 \mathrm{~d}$, respectively, and $2.3-, 3.2-$, and 9.4-fold $(P<0.01)$ expressions of $\alpha_{\mathrm{S}^{2}} \mathrm{CN}$ at 1,2 , and $4 \mathrm{~d}$, respectively. Therefore, it was confirmed that we received MAC-T cells. For the in vitro analyses, MAC-T cells were maintained in Dulbecco's modified Eagle's/high-glucose medium containing $10 \%$ fetal bovine serum, $1 \%$ penicillin-streptomycin, $1 \mu \mathrm{g} /$ $\mathrm{mL}$ hydrocortisone, and $5 \mu \mathrm{g} / \mathrm{mL}$ insulin at $37^{\circ} \mathrm{C}$ in an atmosphere comprising $5 \% \mathrm{CO}_{2}$ and air.

\section{Cell Viability Assay}

The CCK- 8 kit was used to assess cell viability according to the manufacturer's instructions. Briefly, MAC-T cells were seeded in 96-well plates at a density of $1 \times 10^{4}$ cells/well. After an either 24- or 48-h incubation with different concentrations of ZEA $(0,5,10,15$, $20,25,30,50,60$, and $100 \mu M), 10 \mu \mathrm{L}$ of CCK-8 was added to each well, and the cells were incubated for an additional $2.5 \mathrm{~h}$ at $37^{\circ} \mathrm{C}$. The absorbance at $450 \mathrm{~nm}$ was measured with a microplate reader (Eon, BioTek Instruments, Winooski, VT). The cell viability was calculated as follows: (treatment group OD - blank group OD)/(control group OD - blank group OD), where $\mathrm{OD}=$ optical density.

\section{Measurement of ROS Production}

Intracellular ROS levels in MAC-T cells were detected by the specific fluorescent probe dye DCFH-DA (Beyotime) using an active oxygen assay kit according to the 
Table 1. Gene information and PCR primer sequences

\begin{tabular}{|c|c|c|c|c|}
\hline Gene & Forward primer & Reverse primer & $\begin{array}{l}\text { GenBank } \\
\text { accession no. }\end{array}$ & $\begin{array}{l}\text { Product } \\
\text { size (bp) }\end{array}$ \\
\hline$A C T B$ & 5'-CCCTGGAGAAGAGCTACGAG-3' & 5'-GTAGTTTCGTGAATGCCGCAG-3' & NM_173979.3 & 130 \\
\hline GRP78 & 5'-CGACCCCTGACGAAAGACAA-3' & 5'-AGGTGTCAGGCGATTTTGGT-3' & NM_001075148.1 & 198 \\
\hline EIF2A & 5'-TCGTCATGTTGCTGAGGTCT-3' & 5'-GCACCATATCCGGGTCTCTT-3' & NM_175813.2 & 111 \\
\hline ATF6 & 5'-ATATTCCTCCGCCTCCCTGT-3' & 5'-GTCCTTTCCACTTCGTGCCT-3' & XM_024989876.1 & 103 \\
\hline ASK1 & 5'-GCTATGGAAAGGCAGCCAGA-3' & 5'-TCTGCTGACATGGACTCTGG-3' & NM_001144081.2 & 160 \\
\hline CASP3 & 5'-CGAGGCACAGAACTGGACTG-3' & 5'-ATGCGTACAAGAAGTCTGCCT-3' & NM_001077840.1 & 100 \\
\hline
\end{tabular}

manufacturer's instructions. Briefly, once cell densities reached approximately $80 \%$ confluence, the MAC-T cells were seeded in 6 -well plates at a density of $2 \times$ $10^{5}$ /well and cultured for $24 \mathrm{~h}$ in medium containing $30 \mu M$ ZEA. Next, the cells were stained with $10 \mu M$ DCFH-DA. The cells were then incubated for $30 \mathrm{~min}$ at $37^{\circ} \mathrm{C}$ in the dark and subsequently washed with PBS to remove any unincorporated dye. The green fluorescence intensity was measured using the fluorescence microscope functionality of a Cytation 5 cell imaging reader (BioTek Instruments). The data were analyzed using Gen5 3.03 software developed by the manufacturer (BioTek Instruments). Experimental controls consisted of the treatment medium minus ZEA.

\section{Mitochondrial Membrane Potential Assay}

The mitochondrial membrane potential assay uses the fluorescent dye JC-1 (Beyotime), which can be used for early detection of apoptosis. To conduct the assay, the MAC-T cells were seeded in a 6-well plate at a density of $2 \times 10^{5} /$ well. Once the cell density reached approximately $80 \%$ confluence, $30 \mu \mathrm{M}$ ZEA was added, and the cells were cultured for an additional $24 \mathrm{~h}$. The cells were then tested according to the manufacturer's instructions (BioTek Instruments). Observation and detection were performed using the fluorescence microscope functionality of a Cytation 5 imaging reader (BioTek Instruments).

\section{RNA Extraction and Quantitative Real-Time PCR}

Total RNA was isolated using TRIzol reagent (Invitrogen, Carlsbad, CA). The purity of the RNA was assessed using the A260/A280 ratio. All samples measured between 1.8 and 2.0, indicating a high level of purity. Reverse transcription reagents were purchased from Beijing ComWin Biotech Co. Ltd. (Beijing, China). First-strand cDNA was synthesized according to the manufacturer's instructions. The SYBR Green Mix Kit (Trans, Beijing, China) was used to perform the quantitative PCR reactions. The specific primers used in the quantitative PCR are listed in Table 1. The expression levels of each target gene were normalized to the corresponding $\beta$-actin threshold cycle $(\mathrm{CT})$ values using the $2^{-\triangle \Delta \mathrm{CT}}$ comparative method (Livak and Schmittgen, 2001).

\section{Flow Cytometry Detection of Apoptosis}

Apoptosis was determined by staining cells with annexin $\mathrm{V}$ and propidium iodide (PI) using the Annexin V-FITC Apoptosis Detection Kit I (BD Biosciences) according to the manufacturer's instructions. The experiment consisted of 4 groups as follows: control, ZEA, 4-PBA, and ZEA plus 4-PBA (cotreatment). The MAC-T cells were first seeded in 6-well plates. In the ZEA-treated group, MAC-T cells were exposed to ZEA for $24 \mathrm{~h}$. In the group treated with 4-PBA, MAC-T cells were pretreated with 4 -PBA for $1 \mathrm{~h}$. In the group treated with ZEA plus 4-PBA, MAC-T cells were pretreated with 4-PBA for $1 \mathrm{~h}$ and exposed to ZEA for 24 h. After the supernatants were discarded, the cells were centrifuged, resuspended, and incubated for $15 \mathrm{~min}$ in $1 \times$ annexin binding buffer, $5 \mu \mathrm{L}$ of FITC annexin $\mathrm{V}$, and $5 \mu \mathrm{L}$ of PI working solutions. After incubation, the stained cells were analyzed using flow cytometry (Beckman-Coulter, Brea, CA).

\section{Caspase-3 Activity Assay}

Caspase-3 activity was measured using a caspase-3 activity assay kit (Beyotime) according to the manufacturer's instructions. This kit measures the activity of caspase-3, which catalyzes the production of yellow p-nitroaniline by the substrate acetyl-Asp-Glu-Val-Asp p-nitroanilide. Briefly, MAC-T cells were digested with trypsin and centrifuged at $600 \times g$ for $5 \mathrm{~min}$ at $4^{\circ} \mathrm{C}$. The supernatants were carefully aspirated, and cell pellets were washed once with PBS and centrifuged. Next, 100 $\mu \mathrm{L}$ of lysate reagent (included with the kit) was added per 2 million cells, and the cells were resuspended and 
incubated for $15 \mathrm{~min}$ in an ice bath. After centrifugation at $16,000 \times g$ for $15 \mathrm{~min}$ at $4^{\circ} \mathrm{C}$, the supernatants were transferred to a prechilled centrifuge tube. The absorbance of the supernatant was measured at 405 $\mathrm{nm}$ using a microplate reader (BioTek Instruments) because p-nitroaniline has an absorption peak at $405 \mathrm{~nm}$.

\section{Statistical Analyses}

The data between groups was analyzed using SPSS statistical software (version 19.0; SPSS Inc., Chicago, IL). All experiments were repeated with 3 independent replicates. Two treatment effects were evaluated using an independent-sample $t$-test or 1-way ANOVA followed by Duncan's multiple range test. Data are expressed as mean \pm standard error of the mean. Differences of $P<$ 0.05 were considered statistically significant.

\section{RESULTS}

\section{ZEA Reduces MAC-T Cell Viability}

To examine the effect of ZEA on MAC-T cell viability, the CCK- 8 method was used to assess the viability of the cells. As presented in Figure 1, when the cells were treated with ZEA for $24 \mathrm{~h}$, cell viability decreased significantly with increasing ZEA concentrations compared with the control group $(P<0.001)$. At $48 \mathrm{~h}$, as the concentration increased, the viability of the cells further decreased significantly. With the exception of those treated with $5 \mu M$ ZEA, all observed differences were significant compared with the control $(P<0.001)$. Based on these data, $30 \mu M$ ZEA was selected for all subsequent experiments.

\section{ZEA Increases ROS Content in MAC-T Cells}

This study was performed to determine the change in ROS levels after treatment of MAC-T cells with ZEA. The ROS test kit described above was used to assess ROS levels in cells treated with $30 \mu M$ ZEA for 24 and 48 h. Figure 2 shows that the fluorescence intensity within the cells in the ZEA-treated group was higher than that of the control group. The histogram demonstrates that the ROS levels in the ZEA-treated cells increased significantly $(P<0.01)$.

\section{ZEA Reduces Mitochondrial Membrane Potential in MAC-T Cells}

The changes in mitochondrial membrane potential in MAC-T cells treated with ZEA for $24 \mathrm{~h}$ were detected using a JC-1 kit (Beyotime). We found that the mitochondrial membrane potential in the cells of the
ZEA-treated group was significantly less than that in the cells of the control group $(P<0.05$; Figure 3$)$.

\section{Effects of ZEA on ER Stress-Related Gene Expression in MAC-T Cells}

To determine whether ER stress was induced in response to ZEA treatment of MAC-T cells, the expression levels of ER stress-related genes were analyzed by quantitative PCR. As presented in Figure 4, ZEA treatment resulted in a significant upregulation of $G R P$ r 8 $(P<0.05)$, HSP70 $(P<0.01)$, EIF2A $(P<0.05)$,
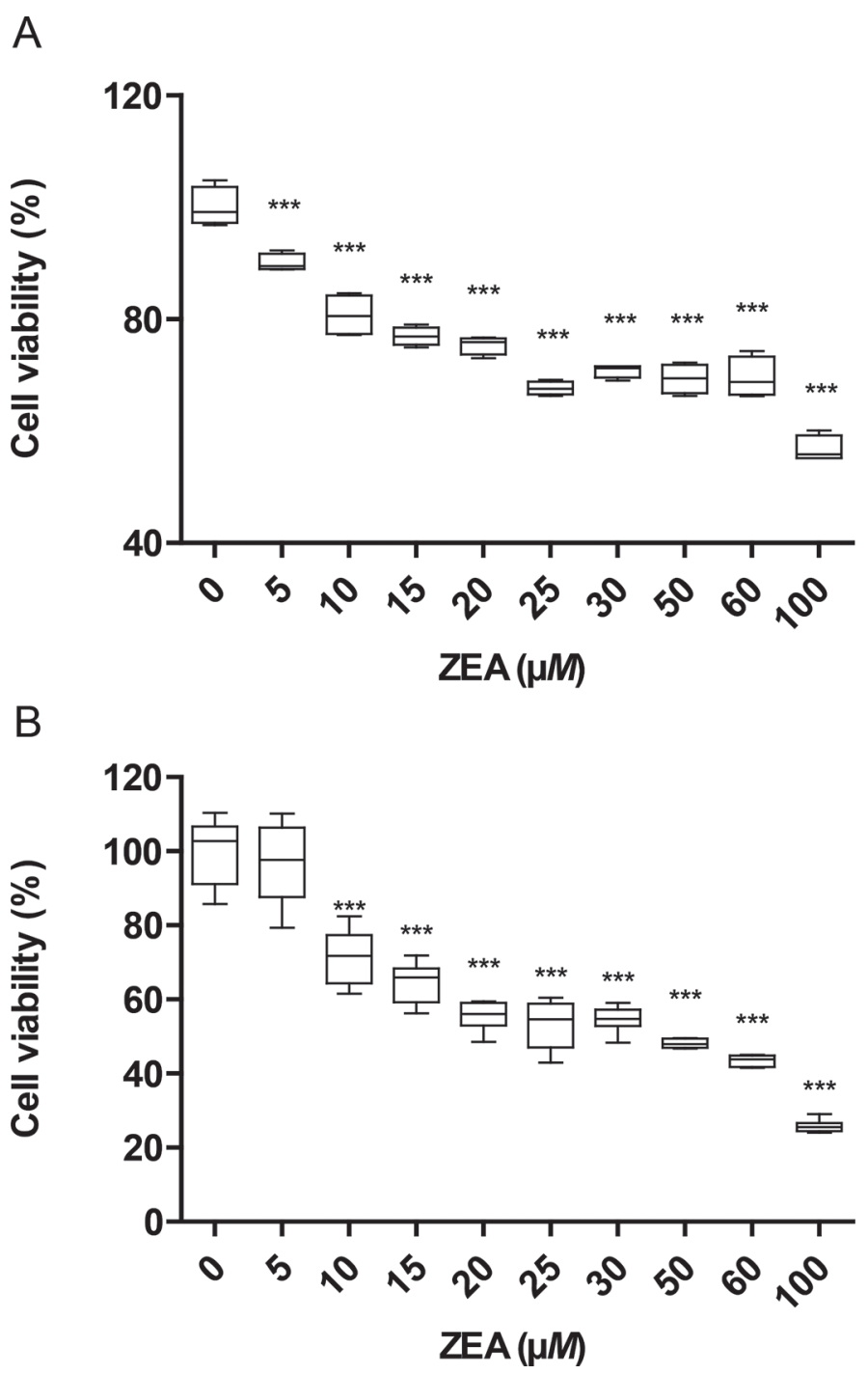

Figure 1. Effects of zearalenone (ZEA) on MAC-T cell viability. Cell viability was measured following treatment with different concentrations $(5,10,15,20,25,30,50,60$, and $100 \mu M)$ of ZEA. (A) 24-h ZEA treatment. (B) 48-h ZEA treatment. Each experiment was repeated 3 times. All values are expressed as means \pm SEM $(\mathrm{n}=$ $3)$. Changes in cell viability were determined by independent-sample $t$-test. ${ }^{* * *} P<0.001$ compared with the control group $(0 \mu M \mathrm{ZEA})$. 
ATF6 $(P<0.05), A S K 1(P<0.01)$, and $C H O P(P<$ $0.001)$. The above results suggest that ZEA induced ER stress in MAC-T cells.

\section{ZEA Induces Apoptosis in MAC-T Cells}

Due to the increase in ROS, decrease in mitochondrial membrane potential, and occurrence of ER stress, we further examined the occurrence of apoptosis in ZEA-treated MAC-T cells. To further confirm that

A
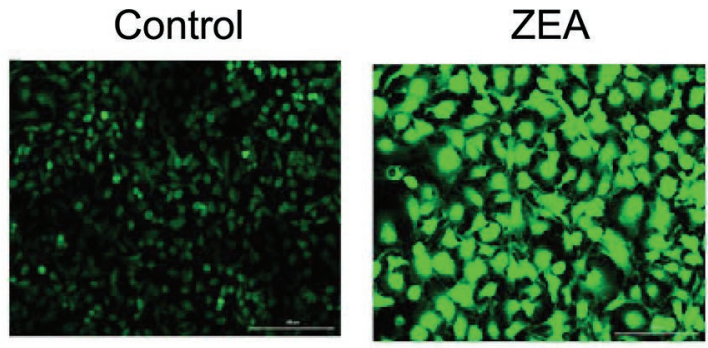

$48 \mathrm{~h}$
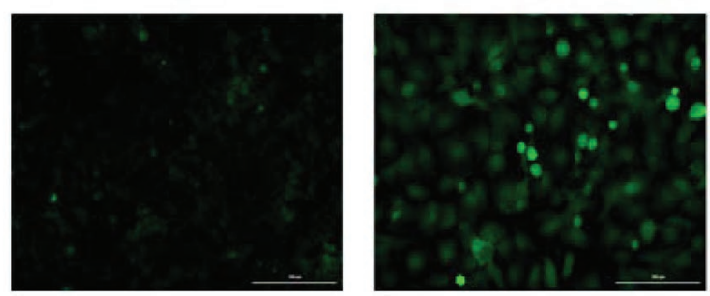

B

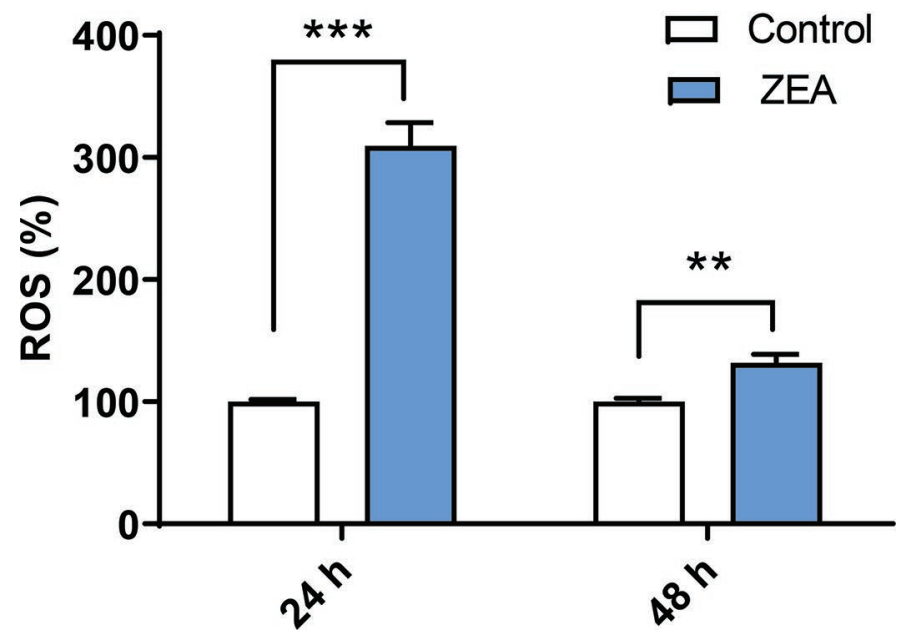

Figure 2. Zearalenone (ZEA)-stimulated increase in reactive oxygen species (ROS) levels in MAC-T cells. In a follow-up trial, cells were treated with $30 \mu \mathrm{M}$ ZEA for 24 or $48 \mathrm{~h}$. (A) Staining of untreated control or ZEA-treated MAC-T cells with the $2^{\prime}, 7^{\prime}$-dichlorofluorescein diacetate probe. (B) Fluorescent intensity data based on the images in Figure 2A. Each experiment was repeated 3 times. All values are expressed as means \pm SEM $(\mathrm{n}=3)$. The expression level of ROS was determined by independent-sample $t$-test. ${ }^{* *} P<0.01$ and ${ }^{* * *} P<$ 0.001 compared with the control group. Scale bar $=200 \mu \mathrm{m}$.
ZEA induces apoptosis in MAC-T cells, flow cytometric analysis was performed to measure the number of apoptotic cells. The results are presented in Figure 5A and B. The total number of apoptotic cells (annexin $\mathrm{V}+$, PI-) increased from $3.67 \%$ to $19.15 \%$. These results indicate that ZEA can induce apoptosis. An increase in the annexin $\mathrm{V}+, \mathrm{PI}+$ population was also observed in MAC-T cells, indicating that late apoptotic cells made up $12.42 \%$ of the population. Furthermore, the changes in caspase- 3 activity after treatment of MAC-T cells with ZEA were examined. As presented in Figure $5 \mathrm{C}$, the ZEA treatment group exhibited a significant increase in the activity of caspase- 3 compared with the control group $(P<0.01)$.

Finally, expression of apoptosis-related genes was examined (Figure 5D). Compared with the control group, the data indicated that $B C L 2$ expression was downregulated $(P<0.001)$, whereas expression of $B A X$ and $C A S P 3$ was upregulated $(P<0.01$ and $P<0.05$, respectively). Taken together, these data suggest that ZEA treatment induced apoptosis in MAC-T cells.

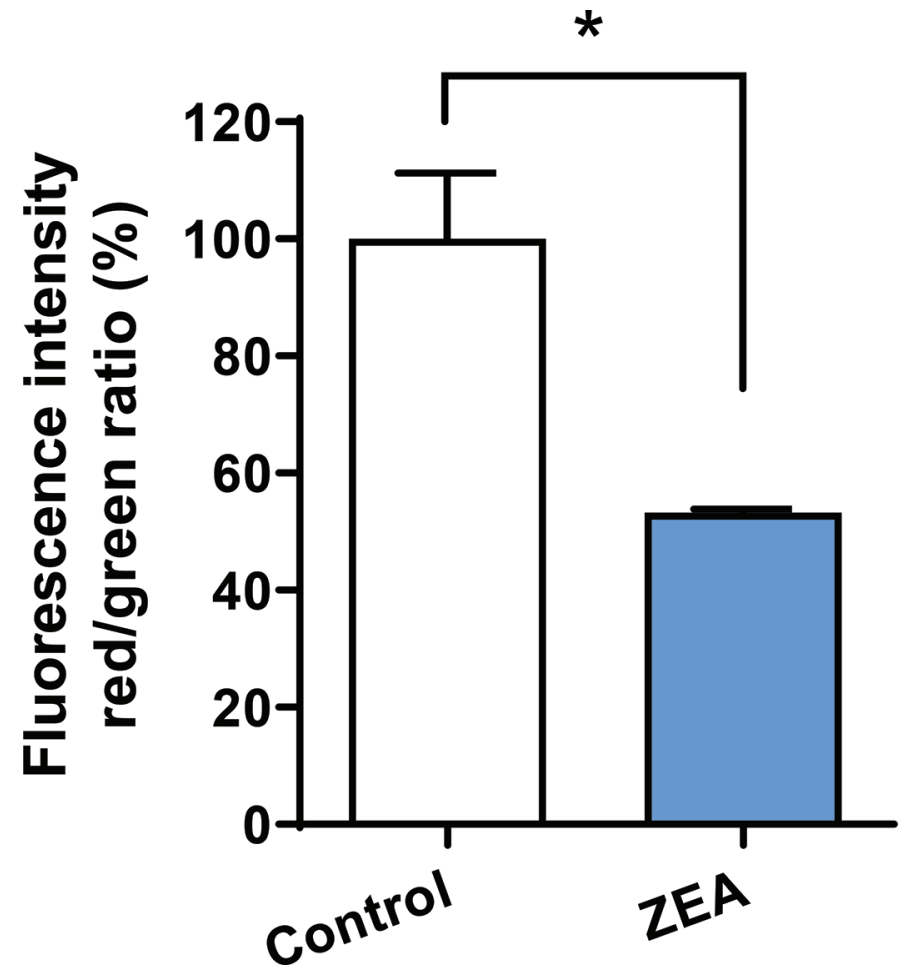

Figure 3. Effect of zearalenone (ZEA) on mitochondrial membrane potential in MAC-T cells. Treatment with ZEA resulted in a decrease in mitochondrial membrane potential compared with untreated cells. Each experiment was repeated 3 times. All values are expressed as means \pm SEM $(\mathrm{n}=3)$. The expression level of mitochondrial membrane potential was determined by independent-sample $t$-test. ${ }^{*} P<$ 0.05 compared with the control group. 


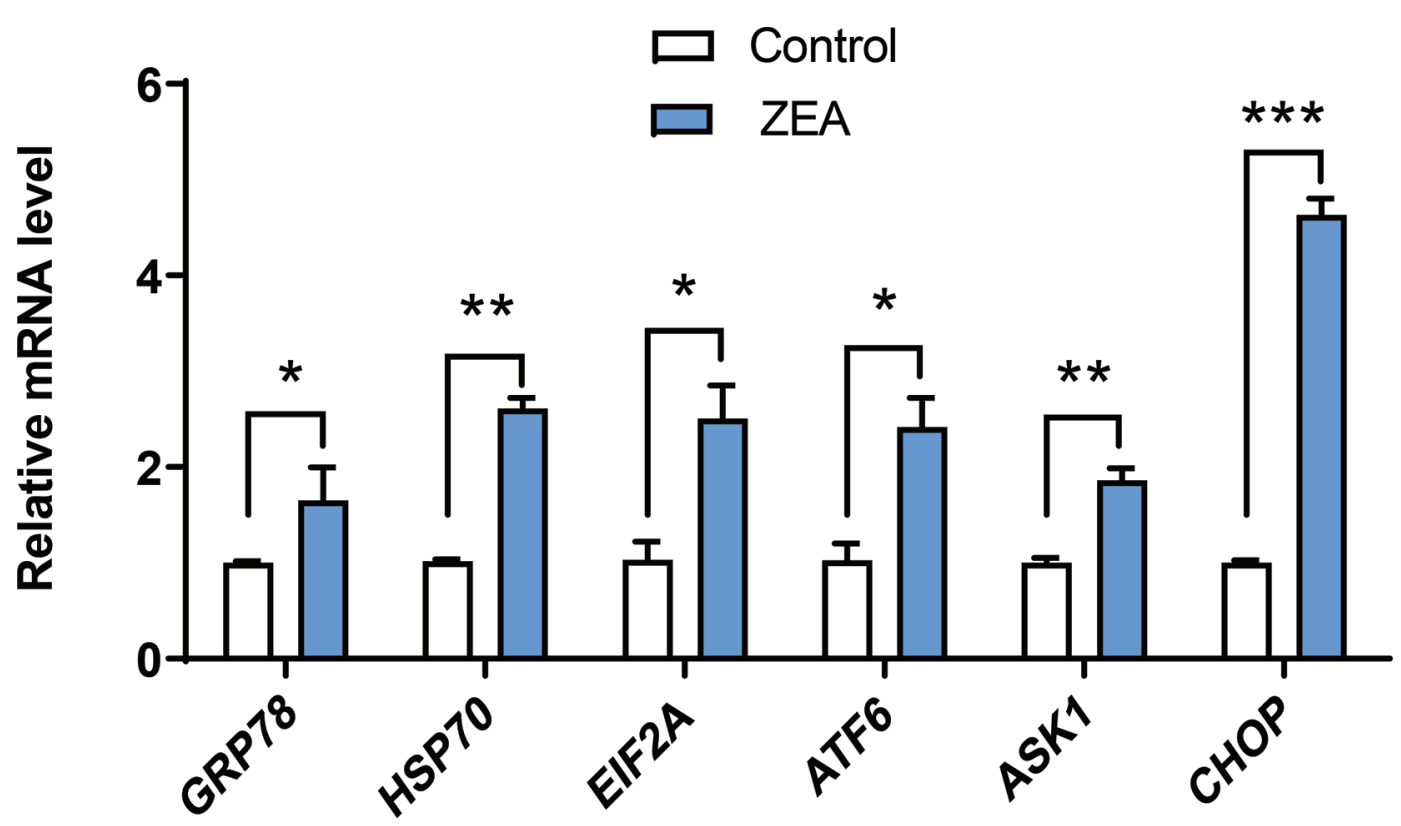

Figure 4. Effects of zearalenone (ZEA) on the expression of endoplasmic reticulum (ER) stress-related genes in MAC-T cells. Cells were treated with $30 \mu M$ ZEA for $24 \mathrm{~h}$. Each experiment was repeated 3 times. All values are expressed as means \pm SEM (n $=3$ ). Gene expression was analyzed by quantitative PCR of the target genes GRP78, HSP70, EIF2A, ASK1, ATF6, and CHOP. The expression level of ER stress-related genes was determined by independent-sample $t$-test. ${ }^{*} P<0.05$, ${ }^{* *} P<0.01$, and ${ }^{* * *} P<0.001$ compared with the control group.

\section{Effect of 4-PBA on MAC-T Cells}

An apoptosis detection kit (BD Biosciences) showed that the apoptotic rate in the group treated with ZEA plus 4-PBA (cotreatment) decreased from $22.23 \%$ to $14.92 \%$ compared with the ZEA-treated group (Figure $6 \mathrm{~A}$ and $\mathrm{B})$. Further tests at the mRNA level revealed that the levels of the ER stress markers CHOP and GRP78 were significantly lower in the cotreatment group compared with the ZEA-treated group $(P<0.01$; Figure $6 \mathrm{C}$ and $\mathrm{D})$. The mRNA level of the apoptosisrelated gene $B A X$ was significantly lower $(P<0.01)$, and the mRNA level of Bcl-2 was higher $(P<0.05$; Figure $6 \mathrm{E}$ and $\mathrm{F}$ ).

\section{DISCUSSION}

An increasing number of studies have shown that there is a significant level of oxidative stress during lactation (Piccione et al., 2008; Zheng et al., 2015). Of particular concern is the fact that the epithelial cells of the mammary gland are both exquisitely susceptible to oxidative stress and the main site for milk synthesis. When the cells are subjected to an oxidative attack, the number of cells will decrease, and an increase in apoptosis is frequently observed (Soberon et al., 2010). In the present study, different concentrations of ZEA were used to treat MAC-T cells. It was observed that cell viability decreased significantly with increasing
ZEA concentration, which is consistent with another previously published report (So et al., 2014). Mechanistically, ROS, the main oxygen-promoting oxide, was produced in excess in response to ZEA treatment, leading to oxidative stress. Here, it was demonstrated that ZEA treatment of MAC-T cells significantly increased ROS levels.

Mitochondria are responsible for supplying the energy needs for various physiological activities ( $\mathrm{Qu}$ et al., 2012). It has been reported that mitochondrial membrane potential is decreased in the human hepatoma cell line HepG2 following treatment with ZEA (Gazzah et al., 2010). Furthermore, mitochondrial membrane potential is an important marker for the detection of early stages of apoptosis in cells. Treatment of MAC-T cells with $30 \mu \mathrm{M}$ ZEA for $24 \mathrm{~h}$ resulted in compromised mitochondrial membrane potential, leading to the induction of the early stages of apoptosis.

It has recently been demonstrated that ER stress occurs in the liver of high-yielding dairy cows and was correlated with the development of liver-related diseases in dairy cows (Gessner et al., 2014; Ringseis et al., 2015). The ER is one of the major sites for the synthesis of milk fat and is an integral organelle contributing to the processing of milk proteins (Akers et al., 2006). Previous reports have demonstrated the role of GRP78 in unfolded protein response and a significant increase in the expression of $C H O P$ under ER stress (Liu et al., 2016). The data presented here indicated that GRPr8 
A

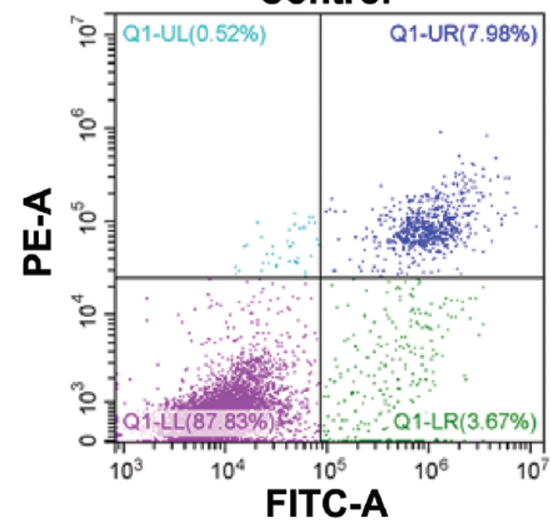

B

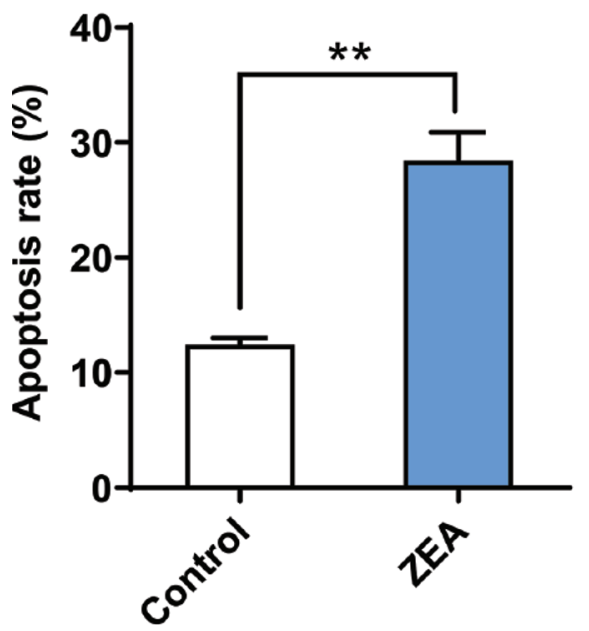

ZEA treated

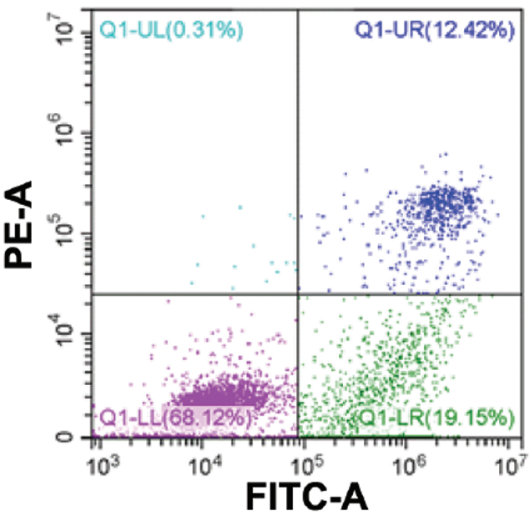

C

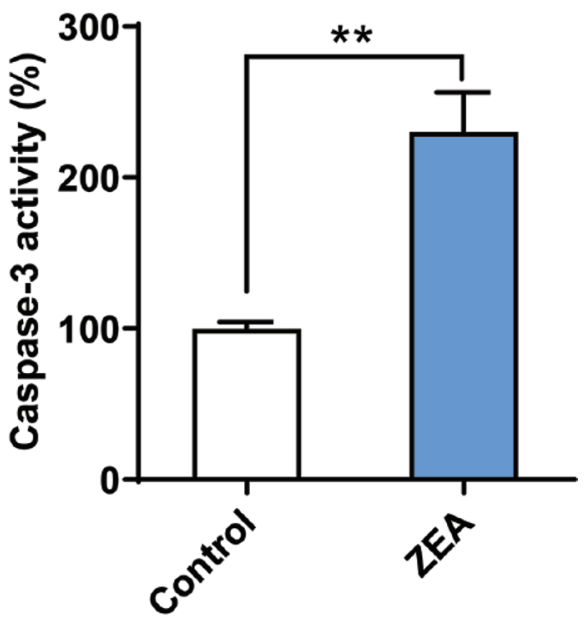

D

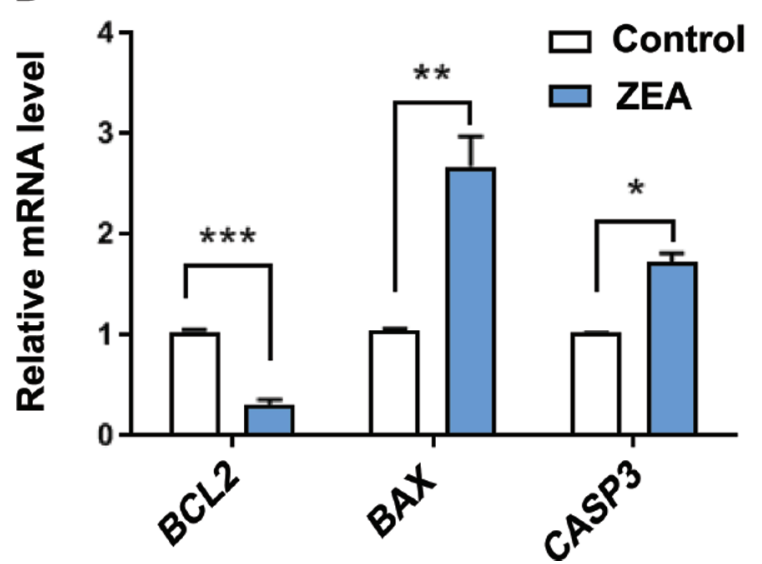

Figure 5. Zearalenone (ZEA)-induced apoptosis in MAC-T cells. (A, B) Flow cytometry results for annexin V and propidium iodide (PI) assay of the control group and ZEA-treated cells after $24 \mathrm{~h}$ of incubation. The lower left area (LL) shows cells that are negative for both annexin V and PI, the lower right area (LR) shows cells that are positive for annexin V, the upper left area (UL) shows cells that are negative for annexin $\mathrm{V}$ and positive for PI, and the upper right area (UR) shows cells that are positive for both annexin V and PI. PE-A indicates PI, and FITC-A indicates fluorescein isothiocyanate. Panel B is the apoptotic rate of MAC-T cells after untreated ZEA and ZEA treatment. (C) A measure of caspase-3 activity according to the caspase-3 activity assay kit (Beyotime, Shanghai, China). (D) The mRNA expression levels of the apoptosis-related genes BCL2, BAX, and CASP3. Quantitative real-time PCR analysis revealed that the BCL2 gene was downregulated and the $B A X$ and $C A S P 3$ genes were upregulated in the ZEA-treated group compared with the control group. Each experiment was repeated 3 times. All values are expressed as means \pm SEM $(\mathrm{n}=3)$. The change in apoptosis was determined by independent-sample $t$-test. ${ }^{*} P<0.05$, ${ }^{* *} P<0.01$, and ${ }^{* * *} P<0.001$ compared with the control group. 


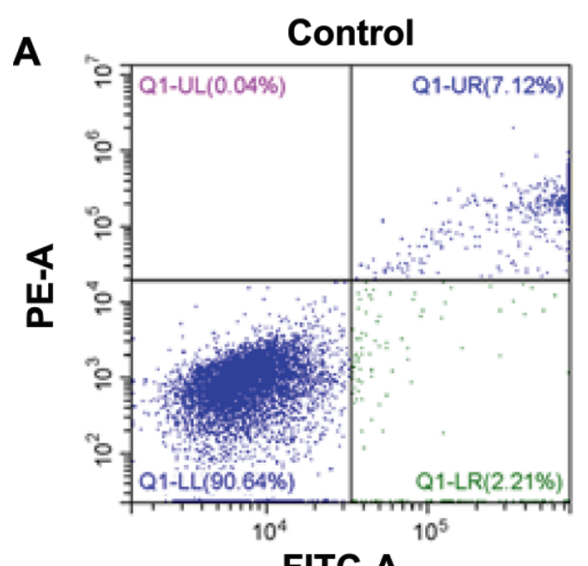

FITC-A

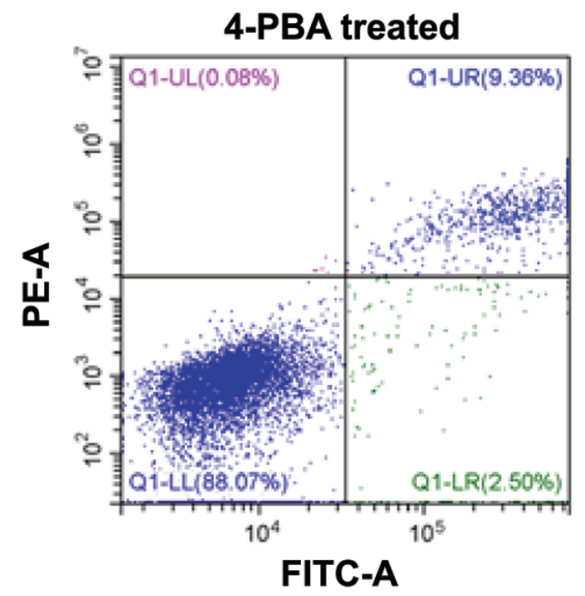

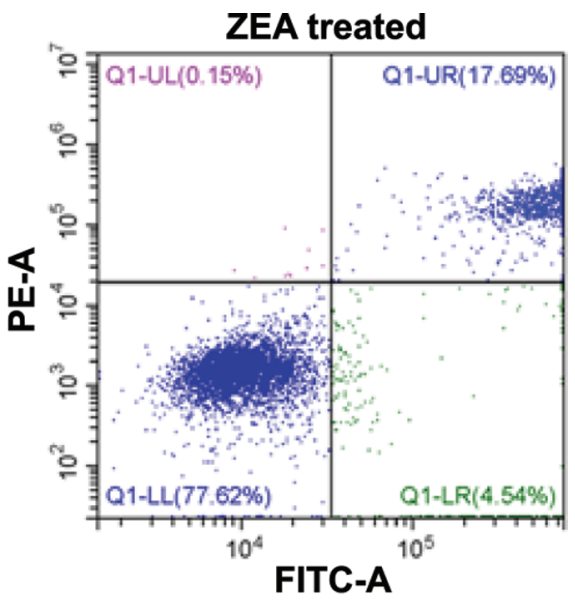

ZEA + 4-PBA treated

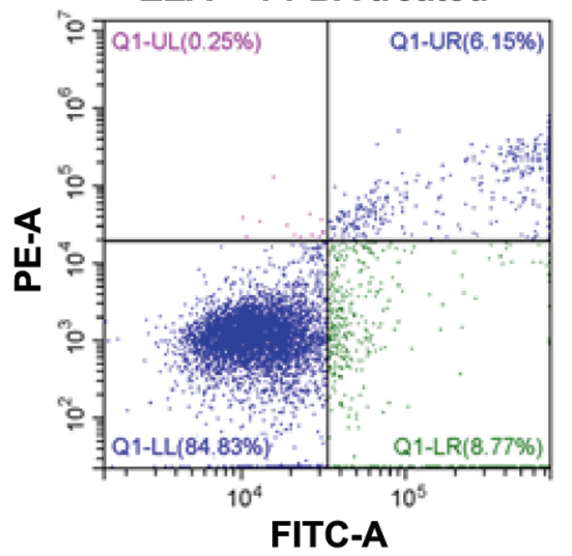

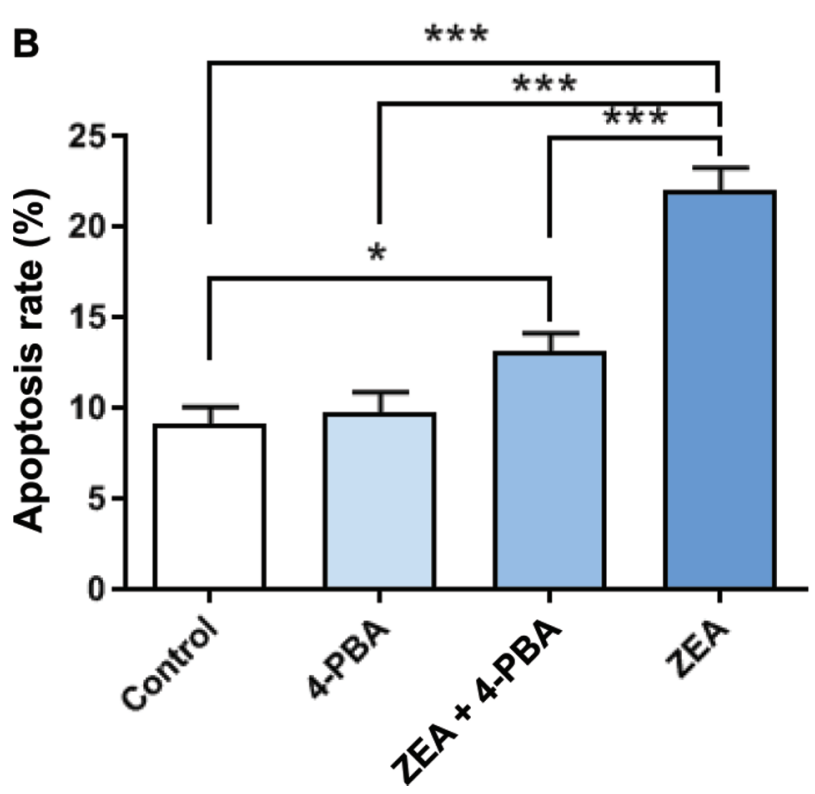

Figure 6. Effect of 4-phenylbutyric acid (4-PBA) on MAC-T cells. (A, B) The annexin V-propidium iodide (PI) flow cytometry assay of the control group, the zearalenone (ZEA)-treated group, the 4-PBA-treated group, and the ZEA + 4-PBA-treated group after $24 \mathrm{~h}$ of incubation. $\mathrm{UL}=$ upper left; $\mathrm{UR}=$ upper right; $\mathrm{LL}=$ lower left; $\mathrm{LR}=$ lower right. PE-A indicates PI, and FITC-A indicates fluorescein isothiocyanate. Panel B is the apoptotic rate of untreated ZEA and 4-PBA, MAC-T cells after ZEA treatment and 4-PBA treatment. (C-F) The mRNA levels of the endoplasmic reticulum stress markers (C) CHOP and (D) GRP78 and the apoptosis-related genes (E) BAX and (F) BCL2. Each experiment was repeated 3 times. All values are expressed as means \pm SEM $(n=3)$. The effect of 4 -PBA was determined by 1 -way ANOVA followed by Duncan's multiple range test. ${ }^{*} P<0.05$, ${ }^{* *} P<0.01$, and ${ }^{* * *} P<0.001$ compared with the control group or the ZEA-treated group. 
gene expression was upregulated. When unfolded proteins accumulate in the lumen of the ER, chaperone proteins will actively bind to the unfolded protein after detachment from the ER membrane. Separation of the chaperone protein activates the ER membrane protein GRP78. Aggregation and activation of transmembrane proteins initiates unfolded protein response, which in turn activates 3 classical transmembrane proteins: PERK, IRE1, and ATF6 (Ron and Walter, 2007). The PERK-EIF-2A-ATF4, ATF6, and IRE1-XBP pathways all activate the downstream $C H O P$ gene. Our data indicate that EIF-2A (downstream of PERK), ASK1 (downstream of IRE1), ATF6, and CHOP were upregulated at the mRNA level. The accumulation of CHOP
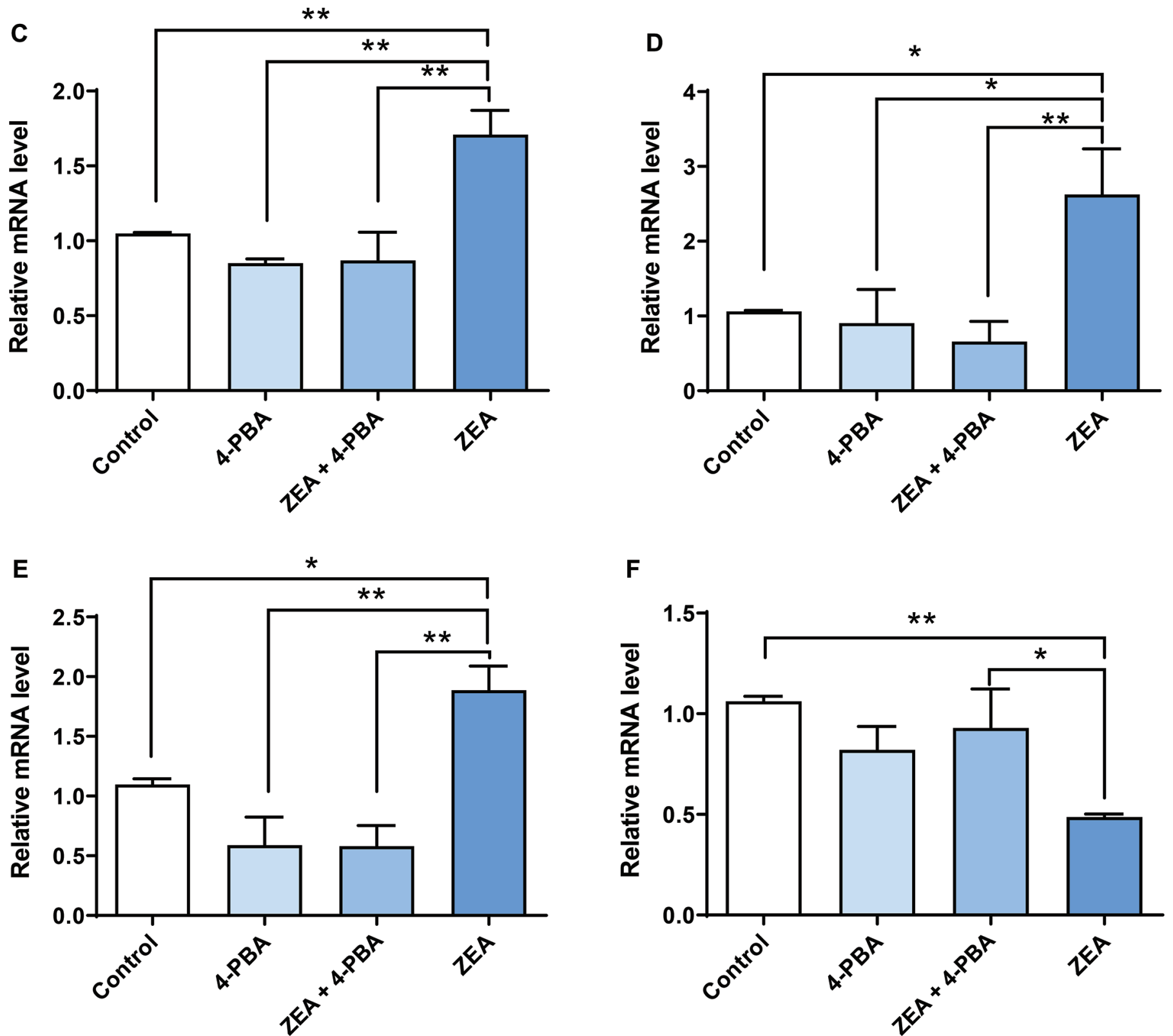

Figure 6 (Continued). Effect of 4-phenylbutyric acid (4-PBA) on MAC-T cells. (A, B) The annexin V-propidium iodide (PI) flow cytometry assay of the control group, the zearalenone (ZEA)-treated group, the 4-PBA-treated group, and the ZEA + 4-PBA-treated group after 24 $\mathrm{h}$ of incubation. $\mathrm{UL}=$ upper left; $\mathrm{UR}=$ upper right; $\mathrm{LL}=$ lower left; $\mathrm{LR}=$ lower right. PE-A indicates PI, and FITC-A indicates fluorescein isothiocyanate. Panel B is the apoptotic rate of untreated ZEA and 4-PBA, MAC-T cells after ZEA treatment and 4-PBA treatment. (C-F) The mRNA levels of the endoplasmic reticulum stress markers (C) CHOP and (D) GRP78 and the apoptosis-related genes (E) BAX and (F) BCL2. Each experiment was repeated 3 times. All values are expressed as means \pm SEM $(n=3)$. The effect of 4-PBA was determined by 1-way ANOVA followed by Duncan's multiple range test. ${ }^{*} P<0.05$, ${ }^{* *} P<0.01$, and ${ }^{* * *} P<0.001$ compared with the control group or the ZEA-treated group. 
resulting from the activation of 3 classical signaling pathways activated by ER stress leads to apoptosis (Lioi et al., 2004b). Studies have shown that the BCL2BAX pathway is involved in ZEA-induced apoptosis in primary rat cells (Li et al., 2011). The caspase family of proteins plays an important role in the initiation of apoptosis, of which caspase- 3 is the primary initiator (Riedl and Salvesen, 2007). Therefore, apoptosisrelated genes were examined here. The data indicated that gene expression of the antiapoptotic factor $B C L 2$ decreased following ZEA treatment. Conversely, the death factor $B A X$ was upregulated, as was CASP3. By upregulating expression of genes associated with ER stress, ZEA indirectly promotes the upregulation of $C H O P$ expression, which further regulates CASP 3 expression through regulation of the apoptotic genes $B C L 2$ and $B A X$. Flow cytometric analysis showed that ZEA treatment induced apoptosis in MAC-T cells, and the results of caspase-3 activity were consistent with the observed mRNA expression, ultimately resulting in apoptotic cell death.

The $70-\mathrm{kDa}$ heat shock protein (HSP70) is a molecular chaperone that secondarily functions to induce responses to cellular stressors, including oxidative stress, hyperthermia, hypoxia, and changes in $\mathrm{pH}$ (Seo et al., 2016). We observed upregulation of $H S P^{r} 70$ gene expression in ZEA-treated MAC-T cells.

In addition, studies have shown the beneficial effects of 4-PBA (ER stress inhibitor) under ER stress (Yang et al., 2017). Our experiments revealed that 4-PBA attenuated ZEA-induced apoptosis in MAC-T cells, which indicates the role of ER stress in ZEA-induced apoptosis.

Feed contamination with ZEA increases the risk of disease in cattle consuming the contaminated feed. Zearalenone was detected in milk and other dairy products (Benkerroum, 2016), and it poses a potential threat to human health. Therefore, it is necessary to gain a deeper understanding of the effects of ZEA on dairy cows, especially on the development of the mammary gland. This study found that ZEA, usually detected as a contaminant in animal feed, induced ER stress and apoptosis in bovine mammary epithelial cells. More studies are needed to develop effective protection measures and subsequently protect the mammary gland from ZEA. We further hope to identify an ideal protective agent that can alleviate the effects of ZEA.

\section{CONCLUSIONS}

Our experiments showed that the treatment of MAC$\mathrm{T}$ cells with ZEA reduced cell viability, increased ROS production, decreased mitochondrial membrane potential, and induced ER stress and apoptosis.

\section{ACKNOWLEDGMENTS}

This research was funded by the Jilin Scientific and Technological Development Program (20170307018NY, 20190301034NY) and the Special Project of the Province-University Co-constructing Program of Jilin Province (SXGJXX2017-4) and was supported by the Open the Northeast Agricultural University/Scientific Observing and Experimental Station of Animal Nutrition and Feed Science in Northeast, Ministry of Agriculture, and the Jilin Modern Agricultural Technology Demonstration and Extension Project (P.R. China).

\section{REFERENCES}

Abassi, H., I. Ayed-Boussema, S. Shirley, S. Abid, H. Bacha, and O. Micheau. 2016. The mycotoxin zearalenone enhances cell proliferation, colony formation and promotes cell migration in the human colon carcinoma cell line HCT116. Toxicol. Lett. 254:1-7. https:// doi.org/10.1016/j.toxlet.2016.04.012.

Akers, R. M., A. V. Capuco, and J. E. Keys. 2006. Mammary histology and alveolar cell differentiation during late gestation and early lactation in mammary tissue of beef and dairy heifers. Livest. Sci. 105:44-49. https://doi.org/10.1016/j.livsci.2006.04.026.

Belli, P., C. Bellaton, J. Durand, S. Balleydier, N. Milhau, M. Mure, J. F. Mornex, M. Benahmed, and C. L. Jan. 2010. Fetal and neonatal exposure to the mycotoxin zearalenone induces phenotypic alterations in adult rat mammary gland. Food Chem. Toxicol. 48:2818 2826. https://doi.org/10.1016/j.fct.2010.07.012.

Ben Salah-Abbès, J., S. Abbès, Z. Houas, M. A. Abdel-Wahhab, and R. Oueslati. 2008. Zearalenone induces immunotoxicity in mice: Possible protective effects of radish extract (Raphanus sativus). J. Pharm. Pharmacol. 60:761-770. https://doi.org/10.1211/jpp.60.6 .0012 .

Benkerroum, N. 2016. Mycotoxins in dairy products: A review. Int Dairy J. 62:63-75. https://doi.org/10.1016/j.idairyj.2016.07.002.

Chen, Y., C. P. Liu, K. F. Xu, X. D. Mao, Y. B. Lu, L. Fang, J. W. Yang, and C. Liu. 2008. Effect of taurine-conjugated ursodeoxycholic acid on endoplasmic reticulum stress and apoptosis induced by advanced glycation end products in cultured mouse podocytes. Am. J. Nephrol. 28:1014-1022. https://doi.org/10 $.1159 / 000148209$.

Endo, M., M. Mori, S. Akira, and T. Gotoh. 2006. C/EBP homologous protein $(\mathrm{CHOP})$ is crucial for the induction of caspase-11 and the pathogenesis of lipopolysaccharide-induced inflammation. J. Immunol. 176:6245-6253. https://doi.org/10.4049/jimmunol.176.10 .6245 .

Farb, R. M., J. L. Mego, and W. Hayes. 1976. Effect of mycotoxins on uptake and degradation of [125I] albumin in mouse liver and kidney lysosomes. J. Toxicol. Environ. Health 1:985-990. https:// doi.org/10.1080/15287397609529401.

Gazzah, A. C., E. E. G. Bennour, C. Bouaziz, S. Abid, M. Ladjimi, and H. Bacha. 2010. Sequential events of apoptosis induced by zearalenone in cultured hepatocarcinoma cells. Mycotoxin Res. 26:187-197. https://doi.org/10.1007/s12550-010-0053-8.

Gessner, D. K., G. Schlegel, R. Ringseis, F. J. Schwarz, and K. Eder. 2014. Up-regulation of endoplasmic reticulum stress induced genes of the unfolded protein response in the liver of periparturient dairy cows. BMC Vet. Res. 10:46. https://doi.org/10.1186/1746-6148-10 -46 .

Jiménez, M., and R. Mateo. 1997. Determination of mycotoxins produced by Fusarium isolates from banana fruits by capillary gas chromatography and high-performance liquid chromatography. J. Chromatogr. A 778:363-372. https://doi.org/10.1016/s0021 -9673(97)00328-2.

Kamp, D. W., G. Liu, P. Cheresh, S. J. Kim, A. Mueller, A. P. Lam, H. Trejo, D. Williams, S. Tulasiram, and M. Baker. 2013. Asbes- 
tos-induced alveolar epithelial cell apoptosis. The role of endoplasmic reticulum stress response. Am. J. Respir. Cell Mol. Biol. 49:892-901. https://doi.org/10.1165/rcmb.2013-0053OC.

Lee, H., C. Kang, Y. S. Yoo, D. Y. Hah, C. H. Kim, E. Kim, and J. S. Kim. 2013. Cytotoxicity and the induction of the stress protein Hsp 70 in Chang liver cells in response to zearalenone-induced oxidative stress. Environ. Toxicol. Pharmacol. 36:732-740. https:/ /doi.org/10.1016/j.etap.2013.06.005.

Lee, Y. L., K. L. Lin, B. N. Wu, S. M. Chuang, W. J. Wu, Y. C. Lee, W. T. Ho, and Y. S. Juan. 2018. Epigallocatechin-3-gallate alleviates bladder overactivity in a rat model with metabolic syndrome and ovarian hormone deficiency through mitochondria apoptosis pathways. Sci. Rep. 8:5358. https://doi.org/10.1038/s41598-018 $-23800-\mathrm{w}$.

Li, G. Y., P. Xie, H. Y. Li, L. Hao, Q. Xiong, and T. Qiu. 2011. Involment of p53, Bax, and Bcl-2 pathway in microcystins-induced apoptosis in rat testis. Environ. Toxicol. 26:111-117. https://doi .org/10.1002/tox.20532.

Lioi, M. B., A. Santoro, R. Barbieri, S. Salzano, and M. V. Ursini. 2004a. Ochratoxin A and zearalenone: A comparative study on genotoxic effects and cell death induced in bovine lymphocytes. Mutat. Res. 557:19-27. https://doi.org/10.1016/j.mrgentox.2003 .09.009.

Lioi, M. B., A. Santoro, R. Barbieri, S. Salzano, and M. V. Ursini. 2004b. Ochratoxin A and zearalenone: A comparative study on genotoxic effects and cell death induced in bovine lymphocytes. Mutat. Res. 557:19-27. https://doi.org/10.1016/j.mrgentox.2003 .09.009.

Liu, M. Q., Z. Chen, and L. X. Chen. 2016. Endoplasmic reticulum stress: A novel mechanism and therapeutic target for cardiovascular diseases. Acta Pharmacol. Sin. 37:425-443. https://doi.org/10 .1038/aps.2015.145.

Livak, K. J., and T. D. Schmittgen. 2001. Analysis of relative gene expression data using real-time quantitative PCR and the 2(-Delta Delta $\mathrm{C}(\mathrm{T})$ ) method. Methods 25:402-408. https://doi.org/10 $.1006 /$ meth.2001.1262.

Miranda, S. G., N. G. Purdie, V. R. Osborne, B. L. Coomber, and J. P. Cant. 2011. Selenomethionine increases proliferation and reduces apoptosis in bovine mammary epithelial cells under oxidative stress. J. Dairy Sci. 94:165-173. https://doi.org/10.3168/jds .2010-3366.

Mori, K., M. Shibanuma, and K. Nose. 2004. Invasive potential induced under long-term oxidative stress in mammary epithelial cells. Cancer Res. 64:7464-7472. https://doi.org/10.1158/0008 -5472.CAN-04-1725.

Piccione, G., S. Casella, A. Assenza, F. Fazio, and G. Caola. 2008. Evaluation of serum homocysteine and oxidative stress during lactation in ewes. Czech J. Anim. Sci. 53:462-465. https://doi.org/10 17221/344-CJAS

Qu, B., Y. Jiang, F. Zhao, J. Xiao, and Q. Z. Li. 2012. Changes of endoplasmic reticulum and mitochondria in mammary epithelial cells during mammogenesis in Chinese Holstein dairy cows. Acta Histochem. 114:448-453. https://doi.org/10.1016/j.acthis.2011.08.007.

Riedl, S. J., and G. S. Salvesen. 2007. The apoptosome: Signalling platform of cell death. Nat. Rev. Mol. Cell Biol. 8:405-413. https: //doi.org/10.1038/nrm2153.

Ringseis, R., D. K. Gessner, and K. Eder. 2015. Molecular insights into the mechanisms of liver-associated diseases in early-lactating dairy cows: Hypothetical role of endoplasmic reticulum stress. J. Anim. Physiol. Anim. Nutr. (Berl.) 99:626-645. https://doi.org/ 10.1111/jpn.12263.

Ron, D., and P. Walter. 2007. Signal integration in the endoplasmic reticulum unfolded protein response. Nat. Rev. Mol. Cell Biol. 8:519-529. https://doi.org/10.1038/nrm2199.
Seo, J. H., J. H. Park, E. J. Lee, T. T. Vo, H. Choi, J. Y. Kim, J. K. Jang, H. J. Wee, H. S. Lee, S. H. Jang, Z. Y. Park, J. Jeong, K. J. Lee, S. H. Seok, J. Y. Park, B. J. Lee, M. N. Lee, G. T. Oh, and K. W. Kim. 2016. ARD1-mediated Hsp70 acetylation balances stress-induced protein refolding and degradation. Nat. Commun. 7:12882. https://doi.org/10.1038/ncomms12882.

Shore, G. C., F. R. Papa, and S. A. Oakes. 2011. Signaling cell death from the endoplasmic reticulum stress response. Curr. Opin. Cell Biol. 23:143-149. https://doi.org/10.1016/j.ceb.2010.11.003.

So, M. Y., Z. Tian, Y. S. Phoon, S. Sha, M. N. Antoniou, J. Zhang, R. S. Wu, and K. C. Tan-Un. 2014. Gene expression profile and toxic effects in human bronchial epithelial cells exposed to zearalenone. PLoS One 9:e96404. https://doi.org/10.1371/journal.pone .0096404

Soberon, F., J. L. Lukas, M. E. V. Amburgh, A. V. Capuco, D. M. Galton, and T. R. Overton. 2010. Effects of increased milking frequency on metabolism and mammary cell proliferation in Holstein dairy cows. J. Dairy Sci. 93:565-573. https://doi.org/10.3168/jds .2009-2345.

Sovolyova, N., S. Healy, A. Samali, and S. E. Logue. 2014. Stressed to death-Mechanisms of ER stress-induced cell death. Biol. Chem. 395:1-13. https://doi.org/10.1515/hsz-2013-0174.

Tan, C., H. Wei, H. Sun, J. Ao, G. Long, S. Jiang, and J. Peng. 2015. Effects of dietary supplementation of oregano essential oil to sows on oxidative stress status, lactation feed intake of sows, and piglet performance. BioMed Res. Int. 2015:525218. https://doi.org/10 $.1155 / 2015 / 525218$

Tatay, E., S. Espín, A. J. García-Fernández, and M. J. Ruiz. 2017. Oxidative damage and disturbance of antioxidant capacity by zearalenone and its metabolites in human cells. Toxicol. In Vitro 45:334-339. https://doi.org/10.1016/j.tiv.2017.04.026.

Tatay, E., G. Font, and M. J. Ruiz. 2016. Cytotoxic effects of zearalenone and its metabolites and antioxidant cell defense in CHO-K1 cells. Food Chem. Toxicol. 96:43-49. https://doi.org/10.1016/j.fct 2016.07.027.

Wang, X., H. Yu, A. Shan, Y. Jin, H. Fang, Y. Zhao, J. Shen, C. Zhou, Y. Zhou, Y. Fu, J. Wang, and J. Zhang. 2018. Toxic effects of zearalenone on intestinal microflora and intestinal mucosal immunity in mice. Food Agric. Immunol. 29:1002-1011. https://doi .org/10.1080/09540105.2018.1503233.

Yang, D., X. Jiang, J. Sun, X. Li, X. Li, R. Jiao, Z. Peng, Y. Li, and W. Bai. 2018. Toxic effects of zearalenone on gametogenesis and embryonic development: A molecular point of review. Food Chem. Toxicol. 119:24-30.

Yang, J., Q. Wu, J. Lv, and H. Nie. 2017. 4-Phenyl butyric acid prevents glucocorticoid-induced osteoblast apoptosis by attenuating endoplasmic reticulum stress. J. Bone Miner. Metab. 35:366-374. https://doi.org/10.1007/s00774-016-0778-3.

Zavizion, B., R. C. Gorewit, and I. Politis. 1995. Subcloning the MAC-T bovine mammary epithelial cell line: Morphology, growth properties, and cytogenetic analysis of clonal cells. J. Dairy Sci 78:515-527. https://doi.org/10.3168/jds.S0022-0302(95)76662-0.

Zheng, G. X., J. T. Lin, W. H. Zheng, J. Cao, and Z. J. Zhao. 2015. Energy intake, oxidative stress and antioxidant in mice during lactation. Zool. Res. 36:95-102. https://doi.org/10.13918/j.issn.2095 $-8137.2015 .2 .95$

Zheng, W. L., B. J. Wang, L. Wang, Y. P. Shan, H. Zou, R. L. Song, T. Wang, J. H. Gu, Y. Yuan, X. Z. Liu, G. Q. Zhu, J. F. Bai, Z. P. Liu, and J. C. Bian. 2018. ROS-mediated cell cycle arrest and apoptosis induced by zearalenone in mouse sertoli cells via ER stress and the ATP/AMPK pathway. Toxins (Basel) 10:E24. https: //doi.org/10.3390/toxins10010024. 